International Journal of Social Science and Economic Research

ISSN: 2455-8834

Volume: 05, Issue: 06 "June 2020"

\title{
AN ECONOMETRIC ANALYSIS OF THE EFFECTS OF THE INCOME PER CAPITA AND EDUCATION TO THE NUMBERS OF CRIME IN AZERBAIJAN
}

\author{
Huseyn Mammadov ${ }^{1}$ \\ ${ }^{1}$ MSc Student in Economics, Department of Economics and Statistics, \\ University of Siena, via Banchi di Sotto 55, 53100 Siena, Italy. \\ DOI: 10.46609/IJSSER.2020.v05i06.016 URL: https://doi.org/10.46609/IJSSER.2020.v05i06.016
}

\begin{abstract}
This analysis illustrates effects of the Income per Capita and Education to the Numbers of Crime in Azerbaijan. The study adopted a quantitative research and data mentioned for the Republic of Azerbaijan between 2005 and 2017 by The State Committee of the Republic of Azerbaijan. The variables used in this study were "Income per Capita" in Euro (dependent variable), "Education level" which I considered higher education as a standard (dependent variable) and "Numbers of Crime" (independent variable). The data was analyzed with using R programming language and Ordinary Least Squares. The main objective of this study is the examine the Effects of the Income per Capita and Education to the Crime Numbers in Azerbaijan. Specially, the study will also investigate the doctor students from higher institutions in Azerbaijan. In the model, I have used the Breusch-Pagan test for heteroskedasticity and The Durbin-Watson test for autocorrelation, after the result I have tried fixed heteroskedasticity and autocorrelation with The Newey-West. Our result allows us to draw a conclusion regarding the effects: there is a negative effect with an inappropriate circumstance.
\end{abstract}

Keywords: $\mathrm{NoC}=$ Numbers of Crime, $\mathrm{IPC}=$ Income per Capita, EL $=$ Number of students from higher educational institutions.

\section{INTRODUCTION}

Randi and Lance (2012) noticed that focusing on growing international evidence that suggest that policies designed to increase educational attainment and improvement on education can significantly reduce crime rates. Benjamin and Jonathan (2013) noticed that the economic factors such as income per capita could be correlated to criminal activity, and the effects of crime on the economy. The present study examines effects of the income per capita and education to the numbers of crime in Azerbaijan. According to the international trend, levels of income per capita 
and education level directly influence to criminal behavior of population. Generally, countries are trying to regulate this problem with investing money to their education for increasing its level and taking income level into consideration for diminishing the number of recorded crimes. In this paper I analyzed same circumstance for Azerbaijan. The Republic of Azerbaijan is in developing countries' list, in developing counties the psychology of population is absolutely different than developed countries, due to this reason I took standards of life from income aspect into account for this case. The data covers the number of students in higher educational institutions, income per person and crime's numbers in Azerbaijan from 2005 to 2017.

https://economics.handels.gu.se/digitalAssets/1439/1439011 49-55 research lochner.pdf

https://mail.google.com/mail/u/0/\#sent?projector=1

\section{PROBLEM SOLUTION}

The data used for this study was gotten from websites https://www.stat.gov.az/ (crime numbers, students from higher education and income per capita between 2005 and 2017) and https://www.cbar.az/home?language=en (exchange rates, that we applied to convert our income per capita in Euro). The data consist of 3 variables which are:

1) $\mathrm{NoC}=$ Numbers of Crime (except governmental issues, for example corruption)

2) $\mathrm{IPC}=$ Income per Capita

3) $E L=$ Number of students from higher educational institutions

\begin{tabular}{|l|l|l|l|}
\hline Year & IPC & EL & NoC \\
\hline 2005 & 808.27 & 129948 & 18049.00 \\
\hline 2006 & 1063.10 & 129141 & 19045.00 \\
\hline 2007 & 1429.10 & 130430 & 18667.00 \\
\hline 2008 & 1951.97 & 136587 & 21692.00 \\
\hline 2009 & 2258.25 & 139194 & 22830.00 \\
\hline 2010 & 2677.56 & 140241 & 23010.00 \\
\hline 2011 & 3047.63 & 143146 & 24263.00 \\
\hline 2012 & 3726.18 & 145584 & 21897.00 \\
\hline 2013 & 3851.98 & 151274 & 22381.00 \\
\hline 2014 & 3993.30 & 158212 & 24607.00 \\
\hline
\end{tabular}


International Journal of Social Science and Economic Research

ISSN: 2455-8834

Volume: 05, Issue: 06 "June 2020"

\begin{tabular}{|l|l|l|l|}
2015 & 3823.89 & 161234 & 26916.00 \\
\hline 2016 & 2648.63 & 163779 & 26611.00 \\
\hline 2017 & 2580.19 & 167677 & 26113.00 \\
\hline
\end{tabular}

\section{METODOLOGY}

$$
\begin{gathered}
\text { OUR MODEL: OLS } \\
\text { NoC }=\boldsymbol{\beta 0}+\boldsymbol{\beta} 1 * \mathbf{I P C}+\boldsymbol{\beta 2} * \mathbf{E L}+\mathbf{e}
\end{gathered}
$$

Heteroskedasticity: The Breusch-Pagan was used to check for heteroskedasticity for this model and the result shows that $\mathrm{P}>0.05$ with $\mathrm{BP}$ test value of 4.5958 which implies that we do not reject the Null hypothesis therefore conclude that there is heteroscedasticity in our model.

$$
\begin{gathered}
\text { data: } \operatorname{lmMod} \\
\mathrm{BP}=\mathbf{4 . 5 9 5 8}, \mathrm{df}=\mathbf{2}, \mathrm{p} \text {-value }=\mathbf{0 . 1 0 0 5}
\end{gathered}
$$

Autocorrelation: The Durbin-Watson statistic was used to check for the presence of autocorrelation in the residuals. The result shows that $\mathrm{p}<0.05$ with which implies that there is evidence of autocorrelation in the model.

$$
\begin{gathered}
\text { data: } \operatorname{lmMod} \\
\mathrm{DW}=\mathbf{1 . 2 2 0 7}, \mathrm{p}-\text { value }=\mathbf{0 . 0 0 9 4 4 5}
\end{gathered}
$$

\section{Estimation of model and result interpretation}

Estimation gives us:

$$
\mathrm{NoC}=-4606+0.32 * \mathrm{IPC}+0.18 * \mathrm{EL}
$$

Therefore the 1-point increase in IPC increases NoC by 0.32 points and 1-point increase in EL increases NoC by 0.18 points. Standard errors for our case are equal to 488.1 and 39.3 for IPC and EL respectively, also from estimation we get that $\mathrm{R}^{\wedge} 2=0.8376$, which, means that PIC and EL are responsible for $84 \%$ of variation of NoC in case of Azerbaijan.

Newey-West: According our results, there are heteroskedasticity and autocorrelation, for that reason I approached to Newey-West for resolving this problem.

Standard error with and without robust standard errors:

\section{S.E. (Newey West) for IPC: 5.0920e-01=0.5}


International Journal of Social Science and Economic Research

ISSN: $2455-8834$

Volume: 05, Issue: 06 "June 2020"

S.E. (without Newey West) for IPC: 4.881e-01=0.4

S.E. (Newey West) for EL: $2.7145 e-02=0.02$

S.E. (without Newey West) for EL: 3.929e-02=0.03

T-value for EL: 6.7043 ----- significant for case.

T-value for PIC: 0.6277 ------- isn't significant for case.

We can assume that overall circumstance for IPC is significant for this case, but it is not significant for EL

R-Programming Language: Graphs
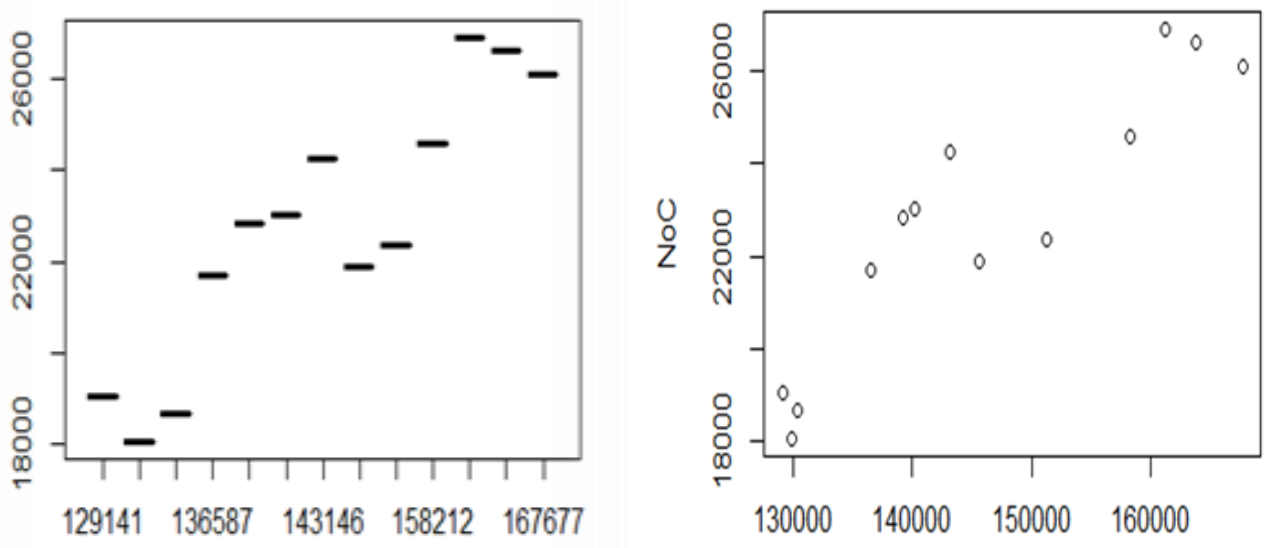

EL

Figure 1 and Figure 2: EL NoC

(Boxplot and Plot) respectively

* We can realize that boxplot is more meaningful and in detail than plot. 


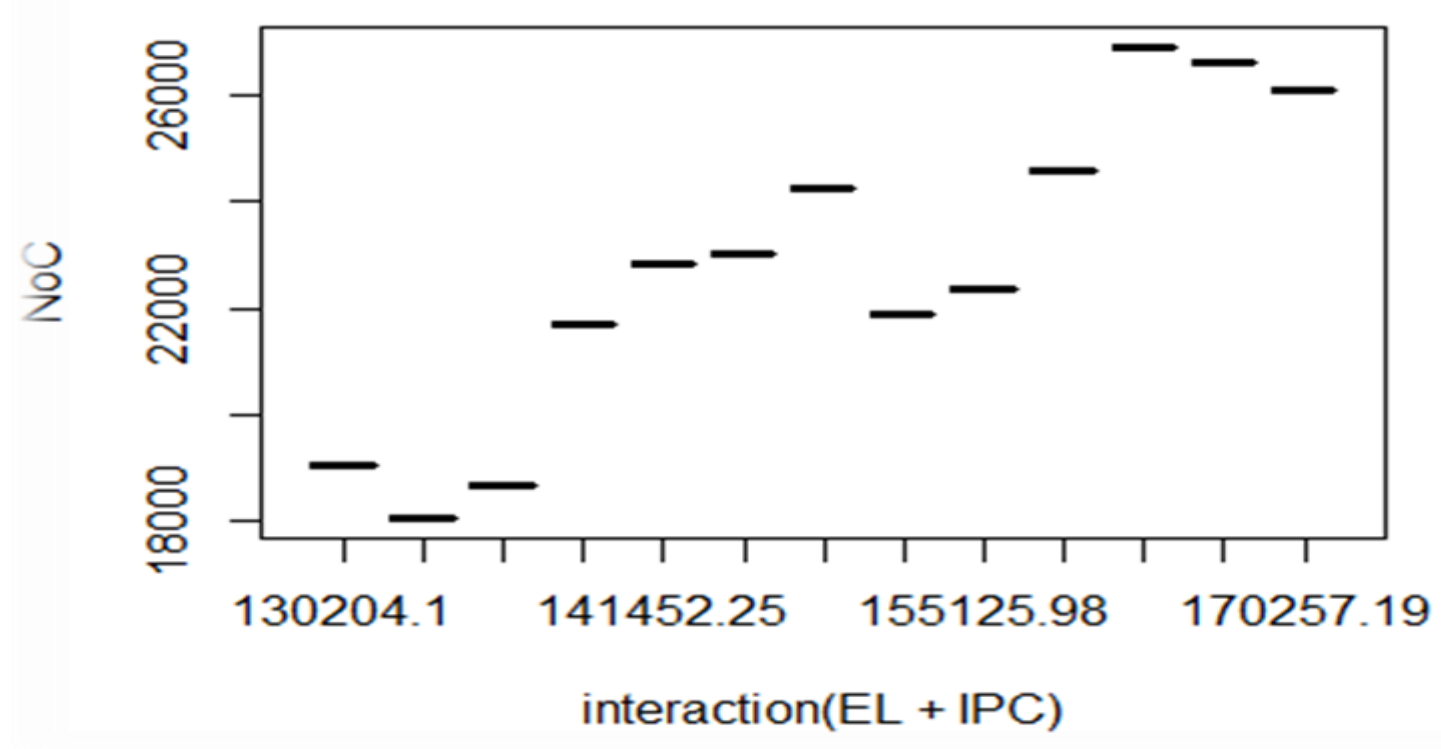

Figure 3: NoC $\sim$ Interaction (EL+IPC)

\section{CONCULUSION}

In this analysis I mentioned effects of the Income per Capita and Number of students from higher educational institutions to the Numbers of Crime in Azerbaijan between 2005 and 2017. Nowadays, there is a circular issue in developing countries' economy, which are corruption and monopoly. I would like to indicate that effect of this issue is on significant level, which we have to take it into consideration. When it comes to my model, for this circumstance I have used the Breusch-Pagan test for heteroskedasticity and The Durbin-Watson test for autocorrelation, after the result I have tried fixed heteroskedasticity and autocorrelation with The Newey-West. Our result allows us to draw several conclusions regarding the effects: 1) there is a negative effect with an inappropriate circumstance, 2) government must regulate it and needs to take every detail into account according to this case. United Nations Human Rights mentions as a key concepts on economic, social rights according to the violation. So, failure to ensure a minimum wage sufficient for a decent living (rights at work), Failure to provide for a reasonable limitation of working hours in the public and private sector (rights at work), Failure to ensure maternity leave for working mothers (protection of and assistance to the family), Failure to prevent employers from discriminating in recruitment (based on sex, disability, race, political opinion, social origin, HIV status, etc.) (The right to work). 


\section{REFERENCES}

1. Article in Center for Analysis of Economic Reforms and Communications Journal: One author Dr. Vusal Musayev 2017 》>Azerbaijan Economic Reforms Review. 《< Strategic Outlook: 7-8.

2. Article in Scientific Journal: More authors. Kanan, Zohrab, Rovshan, Azer. 2013. 〉> Assessment of Economic and Export Diversification Azerbaijan. $\ll$ Economic Diversification: 22-25.

3. Article in CESifo DICE Report: More Authors. Randi Hjalmarsson and Lance Lochner. 2012. >> The Impact of Education on Crime: International Evidence. $<<$ The Economics of Education and Educational Attainment and Crime: 49-52. https://economics.handels.gu.se/digitalAssets/1439/1439011_49-55_research_lochner.pdf

4. Azerbaijan. International Monetary Fund: Republic of Azerbaijan. 2007. IV Consultation-Staff Report; Public Information Notice on the Executive Board Discussion; and Statement by the Executive Director for the Republic of Azerbaijan.

5. Internet webpages: a) Economic Development in Azerbaijan - Asian Development Bank 2019. https://www.adb.org/countries/azerbaijan/main, b) Central Bank of The Republic of Azerbaijan: https://www.cbar.az/home?language=en c) The State Statistical Committee of the Republic of Azerbaijan: https://www.stat.gov.az/index.php d) https://www.ohchr.org/EN/Issues/ESCR/Pages/WhatareexamplesofviolationsofESCR.aspx 